\title{
HR PROFESSIONALS' EFFECTIVENESS AND COMPETENCIES: A PERCEPTUAL STUDY IN THE BANKING SECTOR OF PAKISTAN
}

\author{
Aqeel Ahmad \\ Lahore Leads University \\ Abdul Rashid Kausar \\ University of Management and Technology \\ Sarwar M. Azhar \\ University of Management and Technology
}

\begin{abstract}
This study examines the human resource (HR) Professionals' Effectiveness through the lens of HR Professionals' Competencies and HR Professionals' Willingness. The Human Resource Competency Study model is used in this research, which is modified to include 'Willingness' as an important competency. Impact of HR Professionals' Social (HRSC), HR Professionals' Technical Competencies (HRTC) and HR Professionals' Willingness (HRPW) on HR Professionals' Effectiveness is measured. The study is undertaken using data drawn from the line managers of the largest bank among the privatized banks of Pakistan. It is hypothesized that all HR Professionals' Competencies are equally and strongly related to HR Professionals' Effectiveness which is theoretically associated with organizational performance. The analysis reveals that the HR Professionals' Competencies have a significant high correlation with HR Professionals' Effectiveness. However, this relationship is stronger for HRSC than HRTC or HRPW and within the sub constructs 'Credible Activist' has the stronger relationship contrary to our expectations. It is also concluded that the HR professionals' of the bank are lacking the competencies and hence have a negative impact on their effectiveness in the banking sector of Pakistan. Keeping in mind the relationship between HR Professionals' Effectiveness and organizational performance, the need to enhance HR Professionals' Competencies is highlighted.
\end{abstract}

Keywords: HR Professionals' Competencies; HR Professionals' Effectiveness; Willingness; Bank.

Corresponding author: Aqeel Ahmad; Department of Business Administration, Lahore Leads University, 5 Tipu Block New Garden Town, Lahore, Pakistan; Email: aqeel_pk@hotmail.com 


\section{INTRODUCTION}

As economies shift from agriculture, to industrial to service and now to knowledge base, there is also a desirable need to shift the human resource management (HRM) functions to keep pace with the changes taking place. The shift in HRM functions intuitively argues for a shift in the managerial roles and competencies of the human resource (HR) Professionals' (Lemmergaard, 2009). In the past, HRM function were more oriented to operational aspects of managing the employees, thus necessitating to follow and implement rules and regulation governing employee and organization relationships (Beatty, Huselid, \& Schneier, 2003; Bal, 2011). But now the primary role for HR Professionals' is debatably focused on strategically managing the human resources. Wright and McMahan (1992, pp, 298) define strategic HRM as "the pattern of planned resource deployment and activities intended to enable an organization to achieve its goals". The requirement presented by these authors has extended this statement to include 'influencing the, mind set' as prior to deploying the resources. Therefore, we propose that "strategic human resource management (SHRM) is a planned deployment of human resources and activities by influencing the mindset of the workforce to facilitate the efficient and effective achievement of organizational goals". This role of the HRM of the organization extends to cover the alignment of the HR skill set and behaviors with the strategic needs of the organization, thus making the role of HR professionals central to the organizational competitiveness. In line with this argument, a number of authors have posited that the HR, which an organization possesses, is a key source of the organization (Inyang, 2010). This new view implies a paradigm shift from the HR being an expense to a profit generating resource (Oxman, 2002) especially in a fast changing environment. Ulrich, Allen, Brockbank, Younger, \& Nyman (2009) for example have posited that there is a growing demand for highly skilled and adaptable workforce in the organization. This demand is predicated on the changing business environment with threats of higher levels of competitive rivalry centered on changes in information and communication technology, which has caused an unfavorable dynamics shift in the industry environment (Porter, 2008). This dynamism is occurring in an environment where products, markets and services are highly globalized (Ulrich, Allen, Brockbank, Younger \& Nyman, 2009) therefore, giving a major impetus to the need to bring about changes in the required skill and capabilities set of the organization's HR. In other words the effect of this milieu of changing environment, shifting competitive landscape enjoin upon the organizations to seek to develop new skills, and develop HR functions in order to expand the role of HR as strategic business partner and not only as functional operatives.

The aim of this paper, therefore, is to understand the relationship between HR Professionals' Competencies and their Effectiveness. The ubiquitous desirability of having specific competencies based on context specificity is highlighted in research in area of HRM. However, given the number of competencies proposed by various researchers, the issue of which group of competencies and amongst them which should be focused upon, raises issues of relevance. A way to resolve this could be to ask the employees to inform this debate. Secondly, by repeated studies across context could help focus on the most relevant competencies that create effectiveness within an environmental setting, supplementing the contingency approach. This paper is developed based on two factors. One, the paper attempts to capture the perception of the employees of the organization about the competencies required to create effectiveness in HR Professionals'. Secondly, resorting to the employee's perception to further emphasize the 
competencies they deem important and consider require immediate attention by organizational managers.

The paper has made the choice to seek perception of employees with regard to competencies derived from the latest Ulrich, Brockbank, Johnson \& Younger (2007) model to help answer the issues related to the nature of relationship as perceived by line managers between HR professional's Competencies with HR professionals' Effectiveness. Furthermore, the paper aims to highlight the competencies that are more significant for HR Professionals' Effectiveness.

The choice of the context of this study, the banking and financial sector of Pakistan is significant in view of its past growth and current growth potential. Further, over the past decade the reforms initiated by State Bank of Pakistan (SBP) have indentified the lack of competencies of HR Professionals' as an impediment in the face of growth potential of the banking sector. This observation of weakness of the HR Professionals' attributes and competencies in Pakistan have also been observed and proposed as an impediment to organizational effectiveness (Sharif, Ahmad \& Kausar, 2011). The paper is structured as follows. First the paper will briefly review the banking sector and its role in economic development as well as identify the implications of HR Effectiveness for this sector. Second, the paper will review literature regarding HR Professionals' Competencies and effectiveness. Thereafter, the theoretical model which forms the basis for testable hypotheses will be presented. Research method, the results and discussion will finally make up the rest of the paper.

\subsection{Purpose and Significance of the Study}

The purpose of this study as mentioned earlier is to improve our understanding of the relevance of HR Professionals' Competencies and their relationship with effectiveness. Financial / banking sector around the world has faced the specter of non performing loans (NPLs). One would surmise that the major reason for this would be the level of or the lack of appropriate competencies of those who extended such unrecoverable loans. Given that as it may be, the ball finally must stop at the doorstep of HR Professionals who are tasked with the hiring, training and developing the officers in the banks, and who should be able to maintains, train and develop the personnel keeping in mind the strategic goals and issues confronting the organization. This study, therefore, in utilizing the context of Pakistan serve two purposes. a) Responding to observations that management theory and practice and its impacts may differ from context to context, and therefore these need to be assessed across environments to be able to strengthen theory. b) Propose a model of competencies and effectiveness which may be relevant to countries that are contiguous to Pakistan and especially of South Asian Association for Regional Co-operation (SAARC) ${ }^{2}$ and Developing-8 (D-8) $)^{3}$ economic blocks. This assertion is based on Pakistan regional contextualization, its similarities and developmental levels with the SAARC and D-8 countries making it a significant context for research.

\footnotetext{
Note: An earlier version of this paper was presented in the "Terengganu International Business and Economics Conference 2012" and subsequently included in the publication of the conference).

Afghanistan, Bangladesh, Bhutan, India, Maldives, Nepal, Pakistan, Sri Lanka Bangladesh, Egypt, Indonesia, Iran, Malaysia, Nigeria, Pakistan, Turkey
} 


\subsection{Banking Sector of Pakistan and Human Resource Management}

Within the service sector the $21^{\text {st }}$ century has claimed the rising role of the financial sector such as insurance and banking (Natarajan \& Shekhar, 2000). Janjua (2003) argued that the failure of a single bank can lead to the failure of the entire economy, because banks play a vital role in shaping up the economy of any country. The core function of banking is to bring financial stability. Furthermore, the banks also provide financial resources necessary for economic development of the country e.g. promote capital formation, investment in new enterprises, promotion of trade and industry, development of agriculture and implementation of monetary policy.

So far, as HRM is considered, it has yet to develop well in the banking sector of Pakistan. In the 10 year strategy paper for the banking sector reforms for example, the SBP (2008) mentions that one of the issues and constraints in Pakistan is that bankers consider the lack of competencies of HR Professionals' as the major limitation for growth of the financial sector. Ejaz et al (2009) also points to the fact that HR Professionals' in the Pakistani banks can be more effective if they focus on human relations, attitude, feelings and well-being of the employees. While Mangi, Shah and Ghumro (2012) report that HR Professionals' are not skillful to develop or perform HR good practices. Due to this the employees are dissatisfied and they are unable to deliver what is expected from them. There is enough scope for banks to improve cost efficiency, which can be acquired by corrective measures to improve their HRM practices, best choice for asset portfolio and reduction in NPLs (Bukhari, 2008; Abbas \& Malik, 2010; Khan, Rehman, Rehman, Safwan \& Ahmad, 2011). The data in Table 1.1 indicates that the NPLs in term of percentage have been growing disproportionately in leading large bank in Pakistan. The issue of NPLs as such has gained increasing attention in the last few years in Pakistan. The large amount of NPLs in the banking system reflects a highly negative impact on the future growth of the sector. Even though there could be many reasons for NLPs to occur including global downturn, nevertheless, the core of these can still be traced to the banking professionals' who have been hired and trained under the mandate of the HR Professionals'.

Table 1.1: Non-Performing Loans of Large Private Bank of Pakistan (NPLs in Rupees Billion)

\begin{tabular}{cc}
\hline Years & Non-Performing Loans \\
\hline 2006 & 26.92 \\
2007 & 24.59 \\
2008 & 36.08 \\
2009 & 42.30 \\
2010 & 44.80 \\
\hline
\end{tabular}

Source: Economic Bulletin (2011) 
Thus, while the rising NPLs are hampering the profitability of Pakistani banking sector (Khan, 2010) this problem specifically crops up because of the lack of trained staff in loan disbursement and debt collection. Ahmed (2006) emphasizes that the training and development of banking staff is the function of HR Professionals' within the respective banking institutions. Through training and development HR Professionals' can enhance the capabilities of the employees of their organizations. As has been pointed out there is a strong opinion within the professional circles that loan officers or debt collectors in the Pakistani banking sector are unskilled in their jobs, which could be attributed to the ineffectiveness of the HR Professionals' and consequent increase of NPLs (Awan, 2009; Hussain, 2008).

\section{LITERATURE REVIEW}

The function of HRM in the organizations has changed in line with the shift in the economic activity, which moved from agricultural to industrial to services and now to information technology orientation and focus. In the beginning the HRM (personnel management of old) was considered a staff function and entailed the application and implementation of rules and policies. The role was basically administrative and it was focused in treating the employees as commodity products with no distinguishing attribute or features (Anthony, Perrewe \& Kacmar, 1996). On the other hand, in transitional economies where the activity is shifting from agriculture and industry to service and technology orientation, the researchers as well as practitioners both inside and outside the organizations, have come to realize that the employees are strategic resources in terms of the value that they offer to the organizations with the unique feature of being repositories of knowledge, skills and capabilities. As it is the people who actually implement the strategies by leveraging their skills and capabilities and therefore, the HR professionals who are tasked with managing this resource has become the resource of organizational success. This has necessitated the need for HR professionals to recognize this shift in paradigm and adapt to it. As such in order to improve and enhance HR's organizational contribution, HR professionals will not only need to transform what they do but will need to also recognize that perceptions of their work will have a significant impact on the organizational performance and their effectiveness (Beatty et al., 2003; Kotter, 1982).

\subsection{HR Professionals' Effectiveness}

The notion of managerial effectiveness has been of interest to researchers since the $1960 \mathrm{~s}$ (Worsfold, 1989; Fisher, Merron \& Torbert, 1987; Miner, 1978; Morse \& Wagner, 1978; Mahoney, Jerdee \& Nash, 1960). The recent theorists, management scholars and practitioners have laid a greater emphasis on the effectiveness of managers and their performance especially in developing countries and economies (Copeman, 1971; Kotter, 1982; McCall \& Lombardo, 1983; Margerison \& Kakabadse, 1984). HRM effectiveness can be defined in different ways including the use of organization performance metrics such as return on investment (ROI), productivity etc. and these may be used to indicate the effectiveness of the HRM function including employee selection, development and retention (Guest \& Peccei 1994); or staffing, human resource development, compensation, safety and health management and lastly employee and labor relations (Mondy \& Mondy, 2012). In other words it can be stated that if HRM functions are successfully and effectively carried out, these will reflect on the effectiveness of both the HR Professionals' as well as the organizations. To further this line 
of argument we can propose that HRM effectiveness can be seen as HRM's contribution to a firm's performance (Ruel, Bondarouk \& Velde, 2007). It is nevertheless observable that HRM being a relatively new and evolving management field in Asia, as compared to the western countries, is as yet under researched in these environments (Han, Chou, Chao \& Wright, 2006). Further the knowledge, skills, and capabilities of HR Professionals' who develop and implement HRM practices have also not been thoroughly studied within Asia (Aitchison, 2007; Sharif, et al., 2011). However, in their studies they point to the fact that the main obstacle for HR Professionals' to perform effectively in the organizations is their lack of competencies.

\subsection{HR Professionals' Competencies and the Ulrich Model}

Selmer and Chiu (2004) define competency as the work related personal attributes like knowledge, skills and values that individuals draw upon to do their work well and is focused on the individuals' internal factors. Ulrich and Brockbank (2005) on the other hand, have leveraged these capabilities to the outside in terms of the HR Professionals' role in mastering the knowledge of external realities of the current days business world. If we integrate, the internal capabilities of knowledge, the skill to work with this knowledge and the value system to channel this work, with the realities of the external world, the HR Professionals' should be able to identify how and where they can add value in the firm. Therefore, HR Professionals' will necessarily be required to become active players and partners of business and focus on developing human as well as organizational capabilities that enable an organization to compete now and in the future. Martina, Hana, and Jiri, (2012) argue that competencies identification and its development are important tools of HRM targeted at achieving the strategic goals of the organization. Competencies, i.e. behavior necessary to reach the required level of a HR Professionals' performance, in combination with efficient organization management thus become a critical factor of success and subsequently also a source for competitive advantage. In order to be effective then, the manager must possess the characteristics most often associated with the description of effectiveness. However, it needs to be recognized that the competencies are actually associated with the environments structural requirements and these have been shifting over time. A good model (Ulrich et al., 2007) suggests this shift over time and provides a broad perspective of the evolution of levels, and types of competencies (see Figure 1 below).

The principal objective was to explain the relationship between competency and performance when the competency models were initially made part of HRM domain (Ulrich \& Yeung, 1989; Brewster, Farndale \& van Ommeren, 2000). Caldwell (2010) related that this holds true specially for the primary HR Professionals Competencies model developed by Ulrich and his peers at University of Michigan (Yeung, Woolcock, \& Sullivan, 1996). After the initial model was proposed it has went through various improvements and modifications $(1987,1992,1997$, and 2002) as indicated in Figure 1. 
Figure 1: Models for HR Competencies 1987 to 2002

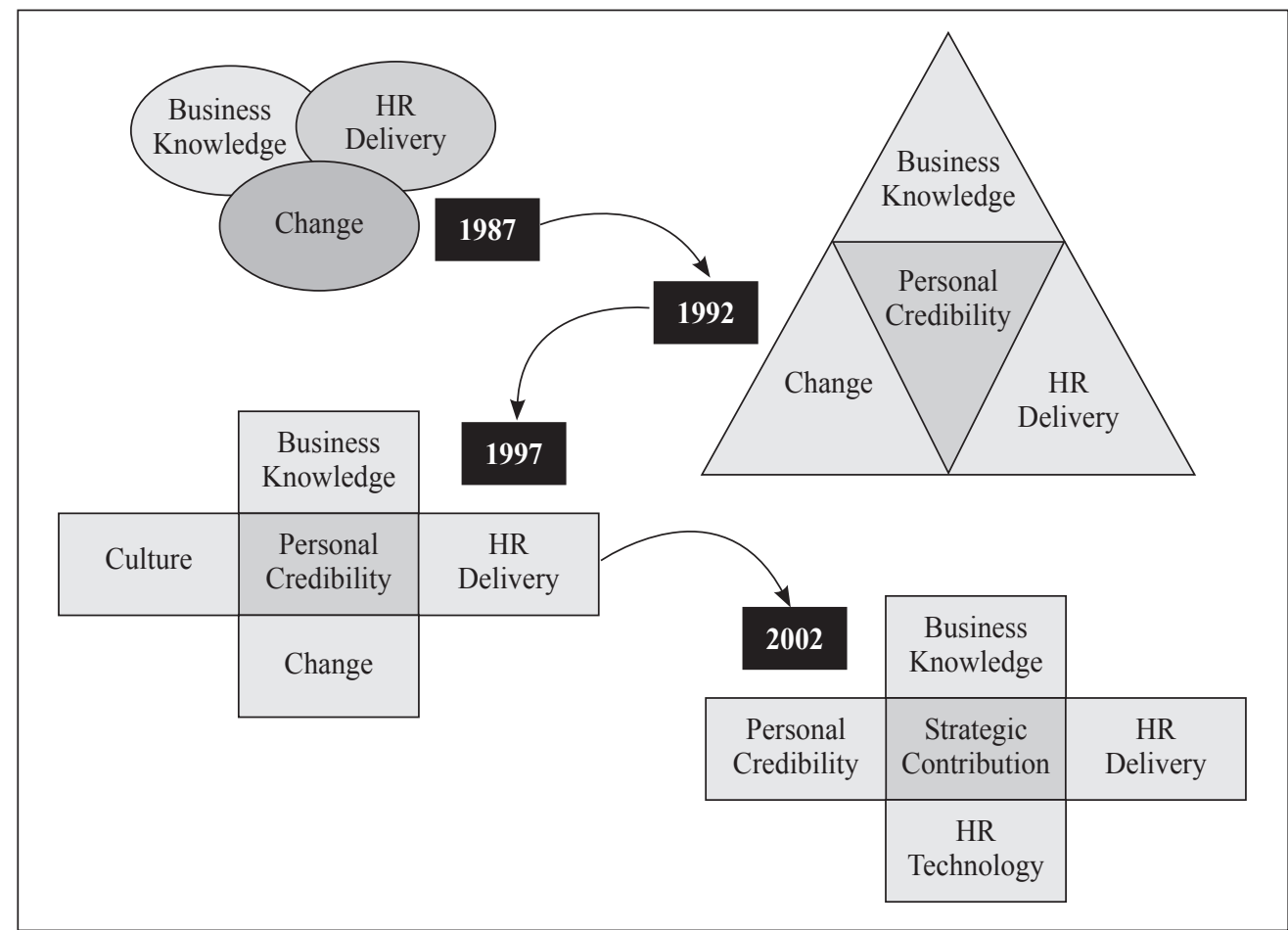

Source: Ulrich, Brockbank, Johnson, Sandholtz \& Younger (2008).

As will be noticed in the beginning it was proposed that there were three important HR professionals' competencies, regardless of the job role or title i.e. 'change management, 'functional expertise' and 'knowledge of the business'4. The recent modification of HR Professionals' Competencies by Ulrich et al., (2008) and his colleagues suggest six competency domains including Credible Activist, Cultural and Change Steward, Talent Manager/ Organizational Designer, Strategic Architect, Business Ally, and Operational Executor. The model proposed by Ulrich et al., (2007) is most pertinent to today's business world and HR Professionals. These HR Professionals' Competencies can be further sub divided using the roles / competencies which can be associated with each level of an organizational structure and system. For example organization capabilities (see Figure 2) are more associated with the strategy formulation and implementation for which the role requirements of being an 'Operational Executor' and Business Ally' are associated with the processes and system of the

${ }_{4}$ It needs to be recognized that this specifically relates to the HRM not 'Personnel Management', which was a processor of the HRM movement. 
organization. While the role needed to manage relationships across the organization is of the 'Credible Activist'. These competencies will be further explicated as the paper proposes its theoretical framework. This paper however, uses Ulrich's (2007) model to define the various role and adds' 'Willingness' as construct to the model. This addition as explained in the next section will form a major contribution to the development of theory for HR Professionals' Competencies.

Figure 2: HR Competency Model by Ulrich et al., (2007)

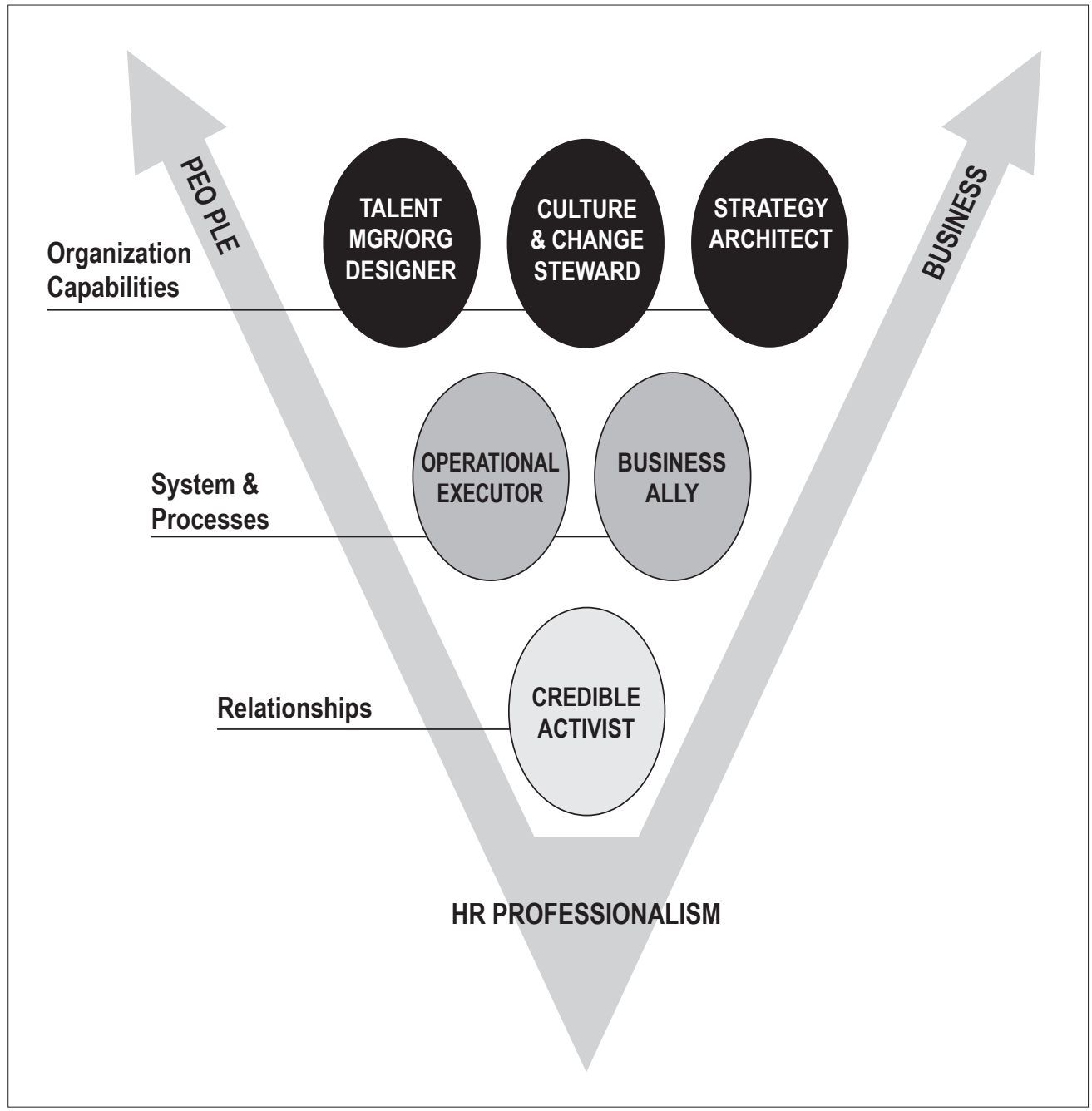

Figure 2: HR Competency Model by Ulrich et al., (2007) 


\subsection{HR Professionals' Willingness}

According to Katz (1964) the work performance of efficiency improves if individuals are 'Willing' to put more effort to the task. According to Currie and Kerrin (2003) one of the reasons of project failures lie in the lack of enthusiasm, uninterested or unwilling behavior at employee's end. In keeping with this general line of argument, we can propose that one way for HR department to add value into the organization is, if HR Professionals is willing to actively contribute to implement the HRM strategies through their competencies to achieve comparative or competitive advantage. Nevertheless, Smith and McLaughlin (2004) suggest that the 'Willingness' factor has in general, not been emphasized in organization knowledge based work and management activities. This paper as indicated earlier, by incorporating 'Willingness' as a distinct competence in the model, aims to respond to this gap.

\subsection{Relationship between HR Professionals' Competencies, HR Professionals'Willingness and HR Professionals' Effectiveness}

According to Ahmad, Kausar \& Sharif (2012) the word 'Will' is associated with intrinsic motivation to be effective or not. Analoui (1998) in his study also found that competencies alone are not adequate to achieve managerial effectiveness as there is a need of 'willingness' from the employee to follow, which plays a vital role in terms of performance. In the same form according to Brockbank (1999) even HR Professionals' have to be 'willing' to obtain competencies if they desire to become highly effective or else projects will fail. According to Ahmad et al., (2012) when the HR Professionals in an organization are enthusiastically involved in execution of HRM strategies it helps to over haul and improve HR department.

\subsection{Theoretical Framework}

Based on the above we can envisage HR Professionals' Effectiveness as a self-reinforcing mechanism of interacting dimensions (i.e. competencies and willingness) such that all of the dimensions work in harmony. For the purposes of testing the model Smith and McLaughlin's construct (2004) for performance has been incorporated with Ulrich et al., HR Competency Model (2007) for HR Professionals' Effectiveness. We have further added willingness as a distinct competency and use the operationalized construct adopted from Smith and McLaughlin (2004).

In this framework model (see Figure 3) the competency construct is divided into social-based and technical-based competencies. Social-based competencies reflect the abilities to manage relationships and interpersonal understanding with employees of the organization while the Technical-based competencies are employed by HR Professionals' to design and develop the organizational HR structure, system and processes. This model also lays out the independent and dependent variables under study. The objective as stated earlier is to understand if a relationship exists and the nature of relationship between the HR Professionals' Competencies proposed by the model and HR Professionals' Effectiveness. Based on the above theoretical model the following hypotheses are proposed. 
Figure.3: Proposed Model for Research

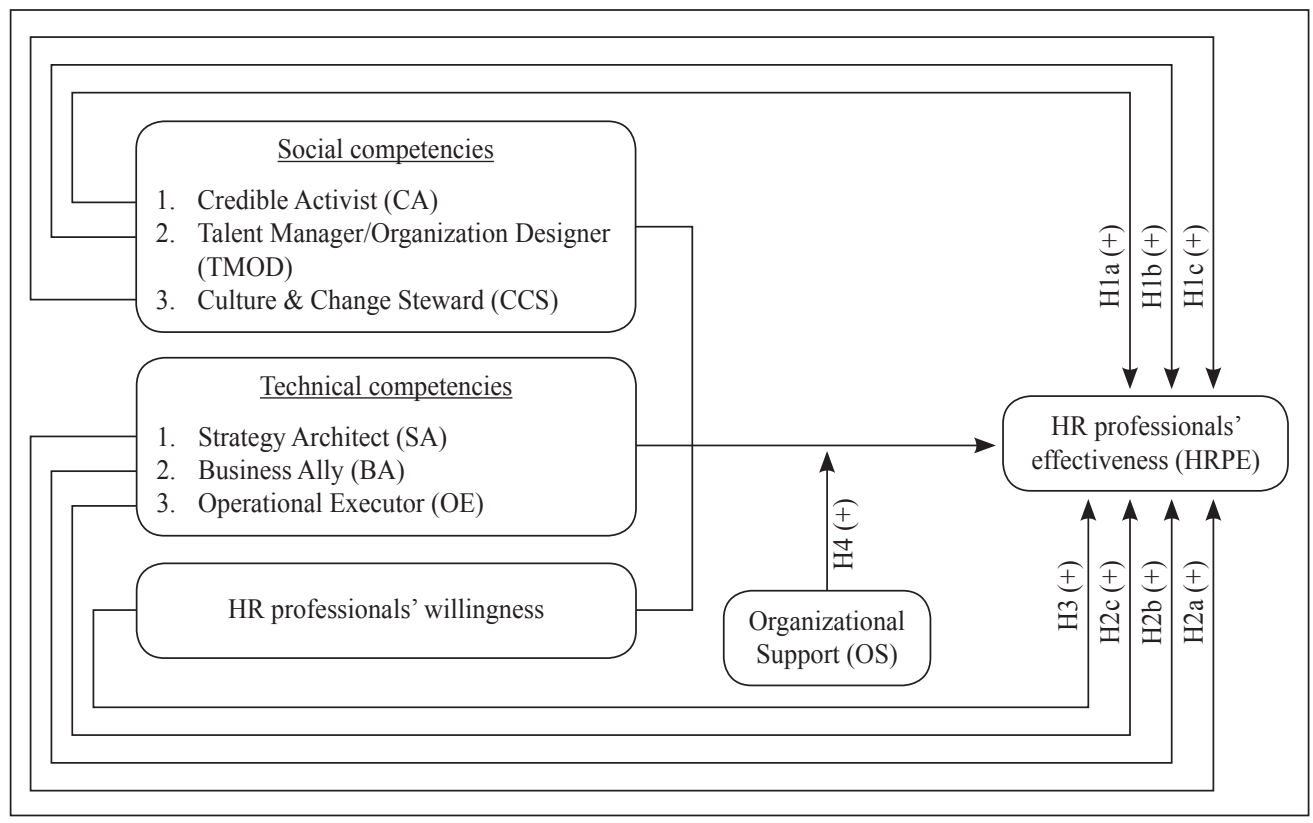

Hypothesis 1: HR Professionals' Social Competencies as defined CA, TMOD \& CCS have a positive relationship with HR Professionals' Effectiveness as perceived by line managers.

Hypothesis 2: HR Professionals' Technical Competencies as defined by SA, BA \& OE have a positive relationship with HR Professionals' Effectiveness as perceived by line managers.

Hypothesis 3: HR Professionals' Willingness has a positively relationship with HR Professionals' Effectiveness as perceived by line managers.

\section{DATA COLLECTION AND ANALYSIS}

A cross sectional survey method is used for the present study and the questionnaire used draws on the previous researches (Sharif \& Ahmad, 2009; Ulrich et al., 2007 and Han et al., 2006) and is adapted through appropriate modification to align with the Pakistani context which helps establish the ecological validity and reliability of the instrument. The questionnaire is made up of four parts namely; Part I) Personal information of the respondents and background section with 5 items; Part II) The HR Professionals' Effectiveness as perceived by the line managers and contains 11 items; Part III) HR Professionals' Competencies and HR Professionals' Willingness as perceived by the line managers comprise of total 65 items. In other words, the survey questionnaire contains total 81 items and was distributed using snowballing technique with the respondents being the individual manager (permanent full time) in a large local privatized bank in Pakistan. 
In the first instance, the data was subjected to reliability analysis using Cronbach Alpha. The overall Alpha for HR Professionals' Effectiveness is reported at (alpha = .935), while the sub constructs of competencies are Credible Activist (alpha = .853), Talent Manager/Organization Designer (alpha = .889), Culture and Change Steward (alpha = .940), Strategy Architect (alpha $=.964)$, Business Ally (alpha value $=.889)$, Operational executor (alpha value $=.898$ ) and HR professionals' willingness $($ alpha $=.942)$. The generally agreed Cronbach's Alpha is 0.60 as an acceptable reliability coefficient (Sekaran, 2005). Therefore, as indicated above the overall Cronbach Alpha of the instrument is 0.985 and the entire scale variables used in the research instrument fall within acceptable limits.

\subsection{Respondents Profile for the Study}

This section describes the demographics of the respondents who participated in this study. The individual characteristics of the respondents such as designation, educational qualification, age, years working in the banking sector and gender are presented in Table 2 below.

Table 2: Profile of the Respondents

\begin{tabular}{|c|c|c|c|}
\hline Variables & Category & Frequency & Percentage \\
\hline \multirow[t]{4}{*}{ Designation } & Branch Manager & 10 & 33.3 \\
\hline & Operations Manager & 12 & 40.0 \\
\hline & Customer Relations Manager & 5 & 16.7 \\
\hline & Credit Manager & 3 & 10.0 \\
\hline Highest & MS/M. Phil & 3 & 10.0 \\
\hline \multirow[t]{2}{*}{ Qualification } & Masters & 23 & 76.7 \\
\hline & Bachelor & 4 & 13.3 \\
\hline \multirow[t]{4}{*}{ Age } & Less than 30 Years & 4 & 13.3 \\
\hline & $30-40$ Years & 8 & 26.7 \\
\hline & 41-50 Years & 7 & 23.3 \\
\hline & More than 50 Years & 11 & 36.7 \\
\hline \multirow{2}{*}{$\begin{array}{l}\text { Years Working } \\
\text { in the }\end{array}$} & 1-3 Years & 2 & 6.7 \\
\hline & 4-6 Years & 2 & 6.7 \\
\hline \multirow[t]{3}{*}{ Banking Sector } & 7-10 Years & 6 & 20.0 \\
\hline & 11-15 Years & 4 & 13.3 \\
\hline & More than 15 Years & 16 & 53.3 \\
\hline \multirow[t]{2}{*}{ Gender } & Male & 24 & 80.0 \\
\hline & Female & 6 & 20.0 \\
\hline
\end{tabular}

The table shows $80 \%$ respondents were males and remaining $20 \%$ respondents were females. The table exhibits that out of the selected sample $40 \%$ respondents were working as Operations Managers, $33 \%$ were working as Branch Managers, $16.7 \%$ were Customer Relation Managers and $10 \%$ Credit Managers. $36.7 \%$ were in the age bracket of above 50 years, $26.7 \%$ respondents 
were between the brackets of 30-40 years, $23.3 \%$ were between the age brackets of 41-50 and respondents below the age bracket of 30 years were $13.3 \%$. The respondents having experience of more than 15 years in banking sector were $53.3 \%$, individuals with 7-10 years of experience were $20 \%$ and ones with 11-15 years were $13.3 \%$. This shows that employees have more than sufficient knowledge regarding their job tasks and activities. $76.7 \%$ of the respondents had a educational qualification of 'Masters', while 13.3\% had a 'Bachelors' degree and 10\% had an MS/M Phil degree.

Table 3 shows the mean score and indicates the extent of respondent's agreement level with the various competencies constructs. The variables that underline the constructs are measured on a five point Likert scale of $1-5$, where 1 represents "Strongly Disagree" and 5 "Strongly Agree". In this regard, any mean scores for the constructs that are below the midpoint (3.00) is considered by the respondents to be low and reflects a weakness in that competence. Mean scores between 3.00 to 3.50 can be seen as indication of moderate level of competence, and the mean scores above 4.00 to 5.00 can be considered as an indication of strength in the competence area as perceived by the responding managers.

Table 3: Descriptive Statistics of the Variables

\begin{tabular}{lcc}
\hline Constructs & Mean & Standard Deviation \\
\hline HR Professionals' Effectiveness (HRPE) & 2.56 & .734 \\
Credible Activist (CA) & 2.89 & .688 \\
Talent Manager /Organization Designer (TMOD) & 2.82 & .623 \\
Culture and Change Steward (CCS) & 2.93 & .650 \\
Strategy Architect (SA) & 2.74 & .739 \\
Business Ally (BA) & 2.77 & .765 \\
Operational Executor (OE) & 3.08 & .645 \\
HR Professionals' Willingness (HRPW) & 2.84 & .874 \\
\hline
\end{tabular}

Table 3 show that the highest mean scores (3.08) is for OE competency as considered by the respondents, thus indicating that the competency of $\mathrm{OE}$ is moderately present in the HR Professionals'. On the other, hand there seems to be a general perception among the respondents that HR Professionals' lack in the other required competencies (CA, TMOD, $\mathrm{CCS}, \mathrm{SA}$ and BA). A similar low opinion is prevalent among the respondent regarding the effectiveness of the HR professionals'. This result may be considered surprising given the highly developed financial sector but seems to be in line with prior research, where HR Professionals' competencies have been reported to be of low level (SBP, 2008; Ejaz et al, 2009; Mangi et al., 2012). The respondents on the other hands seem to also consider that the HR Professionals' are 'unwilling' to either acquire competencies or apply these competencies to help the organization to effectively implement strategies. Given that HR Professionals' score low on both their competencies and their effectiveness in the perceptions of the responding managers, a case can be made that there is a suggestive relationship between HR Professionals' Effectiveness and HR Professionals' Competencies. This proposition finds support from Ulrich, Youner, Brockbank \& Ulrich (2012). However, this aspect is further explored through correlation analysis, which also forms part of the hypotheses testing framwork. 


\subsection{Correlation Analysis}

The Table 4 firstly looks at the relationship between HR Professionals Social Competencies (HRSC) and the proposed constructs of Credible Activist (CA), Talent Manager/Organization Designer (TMOD) and Culture and Change Stewards (CCS). Secondly Table 4 shows the relationship with proposed sub constructs : HR Professionals' Technical Competencies (HRTC) with sub constructs; Strategy Architect (SA), Business Ally (BA) and Operational Executor (OE) and HR Professionals' Willingness (HRPW) with HR Professionals' Effectiveness (HRPE). The hypotheses (H1 - H3) and are analyzed using Pearson Correlation.

Table 4: Relationship of HRSC, HRTC, HRPW with the HRPE

\begin{tabular}{|c|c|c|c|c|c|c|c|c|c|c|}
\hline Variables & HRPE & $\mathbf{C A}$ & TMOD & CCS & HRSC & SA & BA & OE & HRTC & HRPW \\
\hline \multicolumn{11}{|c|}{ Dependent variable } \\
\hline HRPE & 1 & & & & & & & & & \\
\hline \multicolumn{11}{|c|}{ Independent variables } \\
\hline $\mathrm{CA}$ & $.801 * *$ & 1 & & & & & & & & \\
\hline TMOD & $.640 * *$ & $.730 * *$ & 1 & & & & & & & \\
\hline $\mathrm{CCS}$ & $.577 * *$ & $.662 * *$ & $.749 * *$ & 1 & & & & & & \\
\hline HRSC & $.753 * *$ & $.894 * *$ & $.923 * *$ & $.880 * *$ & 1 & & & & & \\
\hline SA & $.531 * *$ & $.596^{* *}$ & $.620 * *$ & $.636^{* *}$ & $.685 * *$ & 1 & & & & \\
\hline BA & $.597 * *$ & $.644 * *$ & $.666^{* *}$ & $.754 * *$ & $.760 * *$ & $.896^{* *}$ & 1 & & & \\
\hline $\mathrm{OE}$ & $.611^{* *}$ & $.644 * *$ & $.660 * *$ & $.482 * *$ & $.669 * *$ & $.578 * *$ & $.567 * *$ & 1 & & \\
\hline HRTC & $.635^{* *}$ & $.691 * *$ & $.715^{* *}$ & $.713 * *$ & $.784 * *$ & $.955^{* *}$ & $.950 * *$ & $.742 * *$ & 1 & \\
\hline HRPW & $.682 * *$ & $.675^{* *}$ & $.624 * *$ & $.603 * *$ & $.706^{* *}$ & $.768 * *$ & $.788 * *$ & $.736 * *$ & $.849 * *$ & 1 \\
\hline
\end{tabular}

Notes: **. Correlation is significant at the 0.01 level (2-tailed).

As shown in Table 4 HRSC has a significant correlation at $0.753(\mathrm{p}<.000)$ with the HRPE. Within the sub competencies of HRSC, the CA is the most highly correlated at $0.801(\mathrm{p}<.000)$ with HRPE followed by TMOD at $0.640(\mathrm{p}<.000)$ and CCS at $0.577(\mathrm{p}<.000)$. From the same (Table 4), we can further note that HRTC also has a significant correlation at 0.635 $(\mathrm{p}<.000)$ with the HRPE. On the other hand, within the sub competencies of HRTC, OE has the highest correlation at $0.611(\mathrm{p}<.000)$ among the sub constructs with the HRPE, $(\mathrm{BA}$ at $0.597(\mathrm{p}<.000)$ and SA at $0.531(\mathrm{p}<.003)$ respectively). Finally, we can observe that HRPW also is significantly correlated at $0.682(\mathrm{p}<.000)$ with the HRPE. Given the above data there is significant support for the purposed hypotheses and as such we fail to reject them.

\section{DISCUSSION}

The surveyed managers' of a large privatized Pakistani bank perceive that competencies as defined by HR Professionals' Social Competencies, HR Professionals' Technical Competencies and HR Professionals' Willingness have a strong relationship with the HR Professionals' Effectiveness. We can observe this phenomenon from the evaluation done by managers of competencies and effectiveness (see Table 3) where both are considered below par. In other words they believe that as there is a lack of professionals' competencies the effectiveness of the function of HRM is also weak and not in line with what is expected or what is necessary to 
create successful organizational performance. The relationship between the effectiveness and the three competencies constructs are also supported by the results of correlation test (see Table 4). In other words, the general perception that all the Social and Technical Competencies are equally relevant and significant for Professionals' Effectiveness, is rejected as in the opinion of employees, 'Social Competencies' consider to more significantly relevant to HR Professionals' Effectiveness than the 'Technical' or 'Willingness' Competency. The rationale to understand this seeming anomaly comes from two points. In 'collectivist' societies (Hofstede et al, 1990) social relationships are more important than 'Technical' which in turn are more significant for 'Individualistic' societies. Second, in the initial stages of introducing or developing a practice there is a strong need for interpersonal connectivity which will have a more profound impact on perceptions of effectiveness than those created by 'Technical' aspects of competencies.

When seeking an answer to the research question two, where the question sought to understand, which of the sub constructs of competencies has a stronger relationship with HR Professionals' Effectiveness, we find that 'Credible Activist' (CA) is highly correlated with the HRPE. In other words, according to the surveyed managers, if, the HR Professionals' are more 'Credible Activists', they will be more effective as professional. This finding is significant, as one would either expect all of the competencies to be valued at the same level in terms of their impact on professional effectiveness as proposed in the literature. In this regard one does not find any specific guide line in the Ulrich et al., (2007) model which may indicates if any of the sub competencies are more significant, than others, thus leading us to assume that they all are equally significant. On the other hand, as proposed by Lawler and Mohrman (2003) and Lawler III and Boudreau (2009) the competency of strategic partners are highly desirable. Within the context of SHRM the 'strategic partner' competency relates to and highlights two sub competencies of the Ulrich et al., (2007) model and these are of 'Strategic Architect' and 'Business Ally' as both relate to the strategic partner concept. Thus one could consider either of the two to be more strongly related to effectiveness of HR professionals'. However, in the context of a developing economy of South Asia and in view of the argument provided above, CA being the most significant competency than all others is worth noting. This same proposition has been forwarded by Grossman (2007) also, who considers CA as the most important competency in terms of professionals' performance. Nevertheless, this relationship can be easily understood in the cultural context of South Asia, which according to Hofstede et al (1990) is more 'collectivist'. In a collectivist framework dependence on others is a significant factor for performance. Therefore, HR Professionals' who are dependable, and are believed to do, what they say will do, will be considered more effective which is also the line taken by Brockbank et al., (2012). They also suggest that HR Professionals' should do what they say they will do. It is important to note that according to us, HR professionals who are credible but not activist are admired but will produce little impact on performance. On the other hand, the HR Professionals' who are activist but may not be credible, would not be able to garner enough trust in their abilities to implement required policies but those who are both activist and dependable will be the one with the most effective performance. The HR professionals thus need to focus on commitments in terms of being supportive of the organizational members and their efforts. Moreover, in all regions (US, Latin America, China, Australia and India) the CA competency is also seen as a positive contributor to bottom line 
result. Further the latest Human Resource Competency Study (HRCS) in 2012 also reports that CA is the more demanded competency required of HR Professionals' for their effectiveness (Ulrich et al., 2012), thus lending support to the findings of this paper.

On the other hand, we have already noted that HRTC has positive relationship with the HRPE. However, within the sub constructs of HRTC the 'Operational Executor' is the more significant in creating professionals' effectiveness the competency whose presence among HR Professionals' is rated higher than all other (see Table 4). In other words, surveyed managers feel that day-to-day activities and policy implementation issues are very important for effective HR Professionals'. This, if seen from the point of view of CA being the most important competency, this perception become further clearer. To the authors it suggests that if professionals are dependable in implementing HR policies and practices they will be more effective, especially where operations are concerned. Reflects the overriding concern for implementing policies and may suggest a lagged affect of the Personnel Management era in managing human resource.

We have already indicated that HR Professionals' Effectiveness as an area of academic research is relatively at early stages most developing countries including Pakistan. In this ongoing work, this emerging area of research should be extended by including other private and public sector organizations. The result of this study can be used as a benchmark for other developing countries, which would need to cross cultural studies to assess and verify these findings.

\section{CONCLUSION}

The study contributes to the literature of HRM on HR Professionals Effectiveness. Furthermore this is primary study effort conducted in banking sector of Pakistan using competency based model of Ulrich et al., (2007) to understand HR Professionals' Effectiveness framework rather than HR practice based assessment. The study finds that the HR Professionals' Competencies including Social, Technical and Willingness have a highly significant correlation with HR Professionals' Effectiveness. However, Social Competencies are more significant in their relationship with HR Professionals' Effectiveness than the other two i.e. HR Technical Competencies and HR Professionals Willingness. Within the sub competencies of HR Professionals' Social Competencies the 'Credible Activist' is the most significant and strongly correlated competency with HR Professionals' Effectiveness. Furthermore, within the sub competencies of HR Professionals' Technical Competencies the 'Operational Executor' has a stronger relationship with HR Professionals' Effectiveness than others. The study also finds the HR Professionals' Competencies are generally lacking in the banking sector in Pakistan as most of the HR Professionals' Competencies as well as their Effectiveness were found to be below the expectation levels of the line managers. This indicates that the HR Professionals' Competencies and their Effectiveness need to be improved further which will ultimately lead to the better organizational performance. A professional value driven HR Professional in the 21 st century should therefore, have the essential HR competencies as indicated by theoretical model to further enhance the level of their effectiveness. 


\section{REFERENCES}

Abbas, K., \& Malik, M. H. (2010). Impact of Financial Liberalization and Deregulation on Banking Sector in Pakistan. Pakistan Institute of Development Economics Working Paper 64.

Ahmad, A., Kausar, A. R., \& Sharif, M. Y. (2012). Preliminary Study of the Moderating Effect of Organizational Support on the Relationship between HR Competencies, HR Willingness and HR professionals' Effectiveness Link: A Study of Line Manager in a Pakistani Banking Sector. Proceedings of $2^{\text {nd }}$ International Conference on Business Management (pp. 1-24). Lahore, Pakistan.

Ahmed, S. (2006). Human Resource Issues in Pakistan. Retrieved, July 22, 2013, from http:// www.nutshellforum.com/article.asp?id=6

Aitchison, D. (2007). HR Transformation: Myth or Reality. HROA Europe and Sharedperise Forums in Association with TPL. Retrieved January 15, 2011, from www.hroassociation. org/uploaded/documents/HR\%20Transformation\%20Myth\%20or\%20Reality.pdf

Analoui, F. (1998). Behavioral and causal influences on individual managerial effectiveness in the Ghanaian public sector. International Journal of Public Sector Management, 11(4), 300-313.

Anthony, W. P., Perrewe, P. L., \& Kacmar, K. M. (1996). Strategic human resource management. USA: The Dryden Press.

Awan, A. G. (2009). Comparison of Islamic and Conventional Banking in Pakistan. Proceedings of 2nd CBRC, Lahore, Pakistan.

Bal, Y. (2011). The new human resources management in the $21^{\text {st }}$ century: a strategic view. Paper presented at Annual Conference on Innovations in Business \& Management, London, UK.

Beatty, R. W., Huselid, M., \& Schneier, C. (2003). New HR metrics. Organizational Dynamics, 32(2) 107-122.

Brewster, C., Farndale, E., \& van Ommeren, J. (2000). HR Competencies and Professional Standards. Cranfield: Cranfield University, Centre for European HRM.

Brockbank, W. (1999). If HR Were Really Strategically Proactive: Present and Future Directions in HR'S Contribution to Competitive Advantage. Journal of Human Resource Management, 38(4), 337-352.

Brockbank, W., Ulrich, D., Younger, J., \& Ulrich, M. (2012). Recent Study Shows Impact of HR Competencies on Business Performance. Employment Relations Today, 1-7. DOI 10.1002/ert.21348 
Bukhari, Z. U. (2008). Key Antecedents of Organizational Citizenship Behavior in the Banking Sector of Pakistan. International Journal of Business and Management, 3(12), 106-115.

Caldwell, R. (2010). Are HR Business Partner Competency Models Effective? Applied HRM Research, 12(1), 40-58.

Copeman, G. (1971). The Chief Executives and Business Growth. London: Leviathan House.

Currie, G., \& Kerrin, M. (2003). Human Resource Management and Knowledge Management: Enhancing Knowledge Sharing in Pharmaceutical Company. The International Journal of Human Resource Management, 14(6), 1027-1045.

Ejaz, S. K., Ejaz, S. A., Rehman, K., \& Zaheer, A. (2009). Evaluating Effective Leadership Qualities of Managers in day-to-day Work of Banking Sector in Pakistan. International Journal of Management and Marketing Research, 2(1), 103-111.

Fisher, D., Merron, K., \& Torbert, W. (1987). Human Development and Managerial Effectiveness. Group Organization Management, 12(3), 257-273.

Grossman, R. J. (2007). New Competencies for HR. HR Magazine, 52(6), 10-11.

Guest, D. E., \& Peccei, R. (1994). The Nature and Causes of Effective Human Resource Management. British Journal of Industrial Relations, 2(32), 219-241.

Han, J., Chou, P., Chao, M., \& Wright, P.M. (2006). The HR Competencies HR Effectiveness Link: A Study in Taiwanese High-Tech. Human Resource Management, 45(3), 391-406.

Hofstede, G., Neuijen, B., Ohayv, D. D., \& Sanders, G. (1990). Measuring Organizational Cultures: A Qualitative and Quantitative Study Across Twenty Cases. Administrative Science Quarterly, 35(2), 286-316.

Hussain, I. (2008). Pakistan's Financial Sector: A Roadmap for 2005-2010 and Concept Paper for Strategic Plan. Retrieved November, 15, 2012, from http:/www.sbp.org.pk/ about/Strategic_Plan_BOD.pdf.

Inyang, B. J. (2010). Strategic Human Resource Management (SHRM): A Paradigm Shift for Achieving Sustaining Competitive Advantage in Organization. International bulletin of Business Administration, 1451-243X(7), 23-36.

Janjua, M. A. (2003). History of the State Bank of Pakistan (1977-1988). Karachi: State Bank Printing Press.

Katz, D. (1964). The motivational basis of organizational behavior. Behavioral Sciences, 9(2). 131-146. 
Khan, M. A., Rehman, K., Rehman, I., Safwan, N., \& Ahmad, A. (2011). Modeling Link between Internal Service Quality in Human Resource Management and Employees Retention: A Case of Pakistani Privatized and Public Sector Banks. African Journal of Business Management, 5(3), 949-959.

Khan, M. A. (2010). Alarming Increasing in Non-performing Loans. Business and Finance Review. Retrieved March, 10, 2011 from http://jang.com.pk/thenews/jan2010-weekly/ busrev-11-01-2010/p11.htm.

Kotter, J. P. (1982). General Managers are not Generalists. Organizational Dynamics, 10(4), 5-19.

Lawler III, E. E., Boudreau, J. W. (2009). What makes HR a Strategic Partner? Center for Effective Organizations. Los Angeles, CA: CEO Publication.

Lawler, E. E., \& Mohrman, S. A. (2003). Creating a strategic human resource organization: an assessment of trends and new directions. Stanford, CA: Stanford University Press.

Lemmergaard, L. (2009). From Administrative Expert to Strategic Partner. Employee Relations 31(2), 182-196.

Mahoney, T. A., Jerdee, T. H., \& Nash, A. N. (1960). Predicting managerial effectiveness. Personnel Psychology, 13(2), 147-163.

Mangi, R. A., Shah, A. A. J. S. A. A., \& Ghumro, I. A. (2012). Human Resource Management Practices in Private Sector Organizations in Pakistan: Study of Culture Influences, Global Journal of Management and Business Research, 12(7), 1-11.

Margerison, C. J., (1984). Chief Executives' Perception of Managerial Success Factors. The Journal of Management Development, 3(4), 47-60.

Martina, K., Hana, U., \& Jiri, F. (2012). Identification of Managerial Competencies in Knowledge-based Organization. Journal of Competitiveness, 4(1), 129-142.

McCall, M. W. Jr., \& Lombardo, M. M. (1983). What Makes a Top Executive? Psychology Today, February, 26-31.

Miner, J. B. (1978). Twenty Years of Research on Role-motivation Theory of Managerial Effectiveness. Personnel Psychology, 31(4), 739-760.

Mondy, R. W., Mondy, J. B. (2012). Human Resource Management (12 ${ }^{\text {th }}$ Ed.). Prentice Hall.

Morse, J. J., \& Wagner, F. R. (1978). Measuring the Process of Managerial Effectiveness. Management Decision, 21(1), 23-35. 
Natarajan, G., \& Shekhar, S. (2000). Knowledge Management: Enabling Business Growth. Boston: McGraw-Hill.

Oxman, J. A. (2002). The Hidden Leverage of Human Capital. Sloan Management Review, 43(4), 79- 83.

Porter, M. F. (2008). The Five Competitive Forces that Shape Strategy. Harvard Business Review, 86(1), 79-93.

Ruel, H. J. M., Bondarouk, T. V., \& Velde, M. V. (2007). The Contribution of e-HRM to HRM Effectiveness; Results from a Quantitative Study in a Dutch Ministry. Employee Relation, 29(3), 280-291.

Sekaran, U. (2005). Research Methods for Business, a Skill Building Approach. New York: JohnWiley \& Sons, Inc.

Selmer, J., \& Chiu, R. (2004). Required Human Resources Competencies in the Future: A Framework for Enveloping HR Executives in Hong Kong. Journal of World Business, 39(4), 324-336.

Sharif, M. Y., \& Ahmad, A. (2009). HR Professionals' Effectiveness in a Knowledge-Based Organization: A Malaysian Case. The International Journal of Knowledge Culture \& Change Management, 8(12), 13-28.

Sharif, M.Y. Ahmad, A., \& Kausar, A. R. (2011). A Comparative Study on the Effectiveness of Human Resource Professionals in Pakistan and Malaysia. IBIMA Business Review, 1-11.

Smith, P. A. C., \& McLaughlin, M. (2004). Knowledge Management: People are Important. Journal of Knowledge Management Practice, 5(January), Retrieve May 15, 2010 from http://www.tlainc.com/artic160.htm.

State Bank of Pakistan (SBP). (2008). Banking Sector Reform: A Vision and Strategy for the Next 10 years. Lahore: Pakistani Press.

Ulrich, D., \& Brockbank, W. (2005). The HR Value Proposition. Boston: Harvard Business School Press.

Ulrich, D., \& Yeung, A. (1989). Human Resources in the 1990: Trends and Required Competencies. Personnel Administrative, March, 38-45.

Ulrich, D., Allen, J., Brockbank, W., Younger, J., \& Nyman, M. (2009). HR Transformation: Building Human Resources from the Outside In. Boston: McGraw Hill. 
Ulrich, D., Brockbank, W., Johnson, D., \& Younger, J. (2007). Human Resource Competencies: Responding to Increased Expectations. Employment Relations Today, 34(3), 1-12.

Ulrich, D., Brockbank, W., Johnson, D., Sandholtz, K. \& Younger, J. (2008). HR Competencies: Mastery at the Intersection of People and Business. Virginia: Society for Human Resource Management.

Ulrich, D., Youner, J., Brockbank, W., \& Ulrich, M. (2012). HR talent and the new HR competenices. Strategic HR Review, 11(4), 217-222.

Worsfold, P. (1989). Leadership and Managerial Effectiveness in the Hospitality Industry. International Journal of Hospitality Management, 8(2), 145-155.

Wright, P. M., McMahan, G. C. (1992). Theoretical Perspective for Strategic Human Resource Management. Journal of Management, 18(2), 295-320.

Yeung, A., Woolcock, P., \& Sullivan, J. (1996). Identifying and Developing HR Competencies for the Future: Key to Sustaining the Transformation of HR Functions. Human Resource Planning, 19(4), 48-58. 